\title{
Chemotherapy of advanced neuroblastoma: does adriamycin contribute?
}

\author{
JACQUES NINANE, JON PRITCHARD, AND JAMES S MALPAS
}

The Hospital for Sick Children, and St Bartholomew's Hospital, London

SUMMARY Between 1970 and 1977, 69 children with newly diagnosed stage III or IV neuroblastoma were treated with pulses of either cyclophosphamide and vincristine $(C V)(n=23)$, or cyclophosphamide, vincristine, and adriamycin (CVA) $(\mathrm{n}=46)$. The 'complete' and partial response rates were 35 and $22 \%$ to $\mathrm{CV}$, and 43 and $26 \%$ to CVA. For 'complete' responders the median time to relapse was 18 months for those treated with $\mathrm{CV}$, and 17 months for those treated with CVA; for partial responders the times were 5 and 7 months respectively. At $2 \frac{1}{2}$ years only $17 \%$ of the CV patients and only $13 \%$ of the CVA patients were alive and free of disease, giving a $15 \%$ overall survival rate. The addition of adriamycin to cyclophosphamide and vincristine did not significantly improve the response rate, duration of response, or survival in these children with advanced neuroblastoma. The previously noted favourable effects of age less than 1 year at diagnosis and of female sex were confirmed. The equally poor survival for stage III and stage IV patients justifies the inclusion of stage III patients in a bad prognosis group.

Despite the use of chemotherapy the treatment of advanced neuroblastoma has remained unsatisfactory and the overall disease-free survival rate for children aged $>1$ year still does not exceed 10 to $15 \% 2$ years after diagnosis. ${ }^{1-3}$ Cyclophosphamide and, to a lesser extent, vincristine, gave fairly good responses when used singly. ${ }^{45}$ When used together, the therapeutic response seemed to be increased ${ }^{6}$ but did not achieve the results obtained in other solid tumours in childhood. ${ }^{78}$ In two studies on single agents, some patients with stage IV neuroblastoma showed some response to adriamcyin, even patients who had been treated with cyclophosphamide and vincristine previously. ${ }^{9}{ }^{10}$ Gasparini et al. ${ }^{11}$ added adriamycin to vincristine and cyclophosphamide in an attempt to increase the overall survival rate of stage IV patients but, although the number of patients reported was small, the results were discouraging. Between January 1970 and June 1977, 69 patients with newly diagnosed advanced neuroblastoma were treated in our two hospitals with pulses of either vincristine and cyclophosphamide (CV), or vincristine, cyclophosphamide, and adriamycin (CVA). Because a retrospective survey showed that the two groups were well matched for age, gender, site of the primary tumour, distribution of metastases, and duration of treatment, it was possible to analyse the effect of adriamycin on the response rate, response duration, and overall survival. In addition, we analysed the series for the effects on prognosis of age, gender, and stage (that is III or IV). Our paper reports the results of this analysis.

\section{Patients and stage}

Patients. All children in this study had been newly diagnosed between January 1970 and June 1977. None had received prior chemotherapy or radiotherapy. At least two of the following three criteria were fulfilled to establish diagnosis: raised level of urinary vanillyl-mandelic acid (VMA), presence of tumour cells in the bone marrow, histological confirmation of the primary tumour. A skeletal survey or an isotopic bone scan (technetium- ${ }^{-99} \mathrm{~m}$ ), and sometimes both, was performed in each case. Other radiological, biochemical, and haematological studies were performed as necessary.

The Evans et al. classification ${ }^{12}$ was used. Stage I, II, and IV-S tumours were excluded. Stage III tumours were tumours without overt metastases, which extended in continuity beyond the mid-line with or without affecting the lymph nodes; in each instance, stage III tumours were initially deemed surgically unresectable. Stage IV patients were those with overt metastatic disease. 


\section{Chemotherapy regimens}

Cyclophosphamide and vincristine $(n=23)$

Patients were treated with pulses of cyclophosphamide $\left(300-600 \mathrm{mg} / \mathrm{m}^{2}\right)$ and vincristine $(1 \cdot 5$ $\mathrm{mg} / \mathrm{m}^{2}$ intravenously, maximum dose $\left.2.0 \mathrm{mg}\right)$. The regimen was repeated every 14 days if possible. The number of pulses given was between 2 and 24 (median 8).

Cyclophosphamide, vincristine, and adriamycin $(n=46)$ Patients were treated with pulses of cyclophosphamide (600 $\mathrm{mg} / \mathrm{m}^{2}$ intravenously), vincristine $\left(1.5 \mathrm{mg} / \mathrm{m}^{2}\right.$ intravenously, maximum dose $\left.2.0 \mathrm{mg}\right)$, and adriamycin $\left(40 \mathrm{mg} / \mathrm{m}^{2}\right)$. The regimen was repeated every 21 days if possible. The number of pulses given was between 2 and 12 (median 7). When the cumulative dose of adriamycin reached $480 \mathrm{mg} / \mathrm{m}^{2}$, the drug was stopped. Some patients still in their first remission were then given $\mathrm{CV}$ for up to 12 further courses.

Additional treatment. Of the 21 patients who had surgery, only 5 (2 in the CV group, 3 in the CVA group) had complete resections of the primary tumour at diagnosis (Table 1$)$. Forty $(56 \%)$ children (16 in the CV group, 24 in the CVA group) received radiotherapy with a cumulative dose range of 400 to 4000 rad. Radiotherapy was given to reduce bulk tumours in 22 patients (10 (43\%) in the CV group, $12(26 \%)$ in the CVA group), and to control any residual disease after a partial excision in 18 other patients $(6(26 \%)$ in the CV group, $12(26 \%)$ in the CVA group). We did not try to analyse the effects of surgery or radiotherapy on the response or survival rates.

\section{Definition of responders}

'Complete' response

'Complete' disappearance of all evidence of primary and metastatic disease with a normal level of VMA.

\section{Partial response}

Disappearance of all evidence of metastatic disease, apart from 'residual' bone changes, more than $50 \%$ shrinkage of primary and more than $50 \%$ decrease in VMA excretion.

\section{No response}

Less than $50 \%$ shrinkage of primary or persistence of metastases or new metastases.

The response to treatment was evaluated after 3 or 4 courses by physical findings, repeated bone
Table 1 Treatment

\begin{tabular}{|c|c|c|c|c|c|c|}
\hline & \multicolumn{2}{|c|}{$\begin{array}{l}\text { Total } \\
(n=69)\end{array}$} & \multicolumn{2}{|c|}{$\begin{array}{l}\text { Cyclophosphamide } \\
\text { and vincristine } \\
(n=23)\end{array}$} & \multirow{2}{*}{\multicolumn{2}{|c|}{$\begin{array}{l}\text { Cyclophosphamide, } \\
\text { vincristine, } \\
\text { and adriamycin } \\
(n=46)\end{array}$}} \\
\hline & \multirow[t]{2}{*}{ No } & \multirow[t]{2}{*}{$(\%)$} & \multirow{2}{*}{ No } & \multirow{2}{*}{$(\%)$} & & \\
\hline & & & & & No & $(\%)$ \\
\hline $\begin{array}{l}\text { Chemotherapy } \\
\text { alone }\end{array}$ & 26 & (38) & 7 & (30) & 19 & (41) \\
\hline $\begin{array}{l}\text { Chemotherapy } \\
\text { and } \\
\text { radiotherapy }\end{array}$ & 22 & (32) & 9 & (39) & 13 & (28) \\
\hline $\begin{array}{l}\text { Chemotherapy } \\
\text { and surgery }\end{array}$ & 3 & (4) & 0 & & 3 & $(6 \cdot 5)$ \\
\hline $\begin{array}{l}\text { surgery, and } \\
\text { radiotherapy }\end{array}$ & 18 & (26) & 7 & (30) & 11 & (24) \\
\hline
\end{tabular}

marrow examination, urinary levels of VMA, and radiological surveys. Because the study ended in 1977, few patients had abdominal ultrasonography or computerised tomography. Therefore, the definition of 'complete' response is clinical rather than the result of exhaustive imaging investigations.

\section{Results}

Characteristics of patients and tumours at diagnosis. The sex and age distribution of patients in the CV and CVA groups were similar. The two groups were also comparable in terms of the proportions with stage III and IV tumours, sites of primary disease, and, for stage IV patients, distribution of metastatic disease (Table 2); in particular, bone metastases were present in all patients. VMA level was significantly raised in $82 \%$ of both groups of patients.

Primary site-stage (Table 2). In most patients, the primary tumour was found to arise within the abdomen, mainly from the suprarenal gland. No primary site could be found in $9 \%$ of cases. Stage IV disease $(88 \%)$ was more common than stage III $(12 \%)$. Among the 61 patients with stage IV disease, there was similar distribution of metastases in bone, bone marrow, lymph nodes, liver, and skin.

Kesponse rate (Table 3). As defined above, $66 \%$ of patients responded to chemotherapy, $41 \%$ completely and $25 \%$ partially. The number of responders, complete and partial, was higher in the CVA than in the CV group but did not reach statistical significance $\left(P>0 \cdot 50, \chi^{2}\right.$ test, $\left.2 \mathrm{df}\right)$.

Relapses. Table 4 gives the time to relapse and the site of relapse for complete and partial responders. All patients with partial responses 'relapsed' within 
a median time of 6 months, most of them at the primary site. Sixty-four per cent of the complete responders relapsed with a median time to relapse of 17 months. In these patients, relapse occurred much less often at the primary site; 6 ( 2 in the CV group, 4 in the CVA group) relapsed in both sites. These results are almost identical in the CV and CVA groups.

Table 2 Primary site, stage, metastases

\begin{tabular}{|c|c|c|c|c|c|c|}
\hline & \multicolumn{2}{|c|}{$\begin{array}{l}\text { Total } \\
(n=69)\end{array}$} & \multicolumn{2}{|c|}{$\begin{array}{l}\text { Cyclophosphamide } \\
\text { and vincristine } \\
(n=23)\end{array}$} & \multirow{2}{*}{\multicolumn{2}{|c|}{$\begin{array}{l}\text { Cyclophosphamide, } \\
\text { vincristine, } \\
\text { and adriamycin } \\
(n=46)\end{array}$}} \\
\hline & \multirow[t]{2}{*}{ No } & \multirow[t]{2}{*}{$(\%)$} & \multirow{2}{*}{$N o$} & \multirow{2}{*}{$(\%)$} & & \\
\hline & & & & & No & $(\%)$ \\
\hline \multicolumn{7}{|l|}{ Primary site } \\
\hline Mediastinum & 9 & (13) & 3 & (13) & 6 & (13) \\
\hline & 50 & (73) & 15 & (65) & 35 & (76) \\
\hline gland) & 44 & (64) & 12 & (52) & 32 & (70) \\
\hline Pelvis & 4 & ( 6$)$ & 2 & (9) & 2 & (4) \\
\hline Unknown & 6 & (9) & 3 & (13) & 3 & ( 7) \\
\hline \multicolumn{7}{|l|}{ Stage } \\
\hline III & 8 & (12) & 2 & (9) & 6 & (13) \\
\hline IV & 61 & (88) & $2 \overline{1}$ & (91) & 40 & (87) \\
\hline \multicolumn{7}{|c|}{ Metastases (stage IV) } \\
\hline Total & 61 & & 21 & & 40 & \\
\hline Bones & 61 & $(100)$ & 21 & $(100)$ & 40 & $(100)$ \\
\hline Bone marrow & 40 & $(66)$ & 13 & (62) & 27 & (68) \\
\hline Lymph nodes & 32 & (52) & 10 & (48) & 22 & (55) \\
\hline Liver & 22 & (36) & 7 & (33) & 15 & (37) \\
\hline Skin & 6 & (10) & 2 & (10) & 4 & (10) \\
\hline
\end{tabular}

Table 3 Response rate

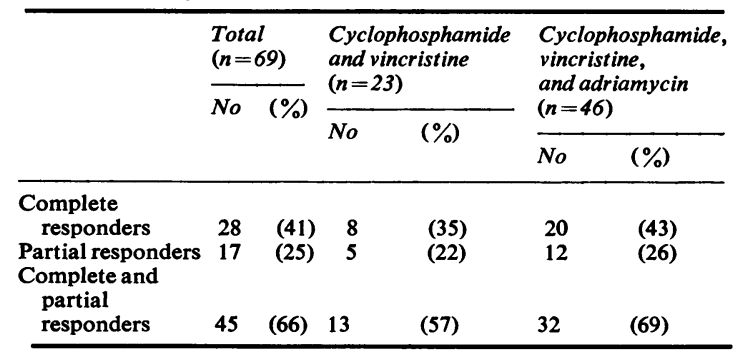

Survival rate. Because no patient died from disease later than 30 months after diagnosis the survival rate was analysed at $2 \frac{1}{2}$ years (Fig. 1). The total survival rate free of disease was found to be between 15 and $17 \%$ for CV-treated patients, and $13 \%$ for patients receiving CVA. Among the 28 complete responders, this survival rate was between 36 and $50 \%$ in the CV group, and $30 \%$ in the CVA group.

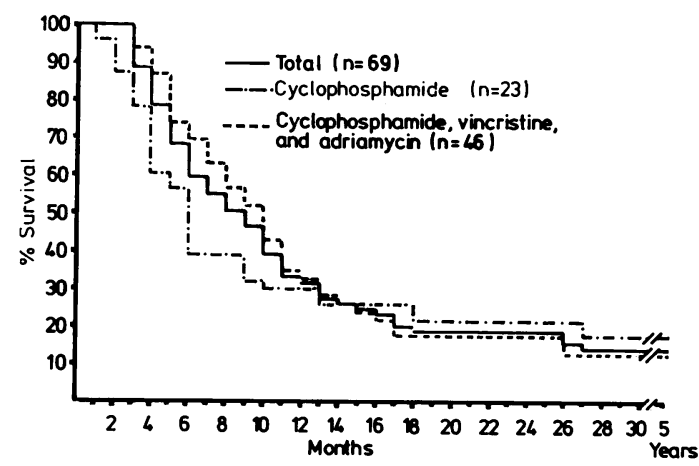

Fig. 1 Survival rate and the effect of adriamycin.

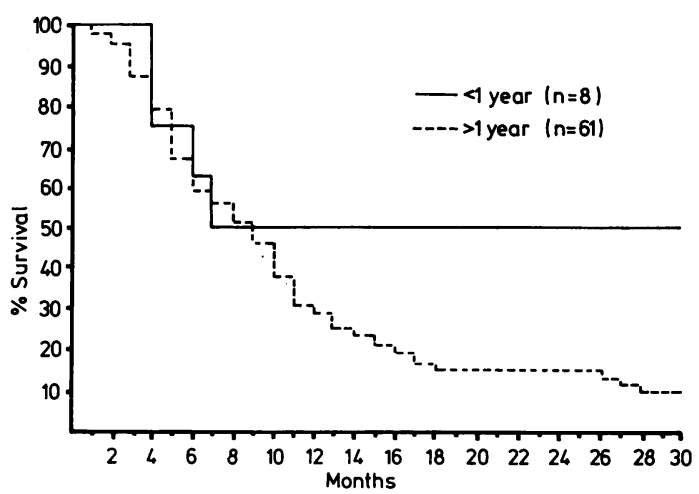

Fig. 2 Effect of age on the survival rate.

Table 4 Relapses

\begin{tabular}{|c|c|c|c|}
\hline & Total & $\begin{array}{l}\text { Cyclophosphamide } \\
\text { and vincristine }\end{array}$ & $\begin{array}{l}\text { Cyclophosphamide, } \\
\text { vincristine, and adriamycin }\end{array}$ \\
\hline $\begin{array}{l}\text { After complete response } \\
\text { Primary site } \\
\text { Metastases }\end{array}$ & $\left.\begin{array}{l}28 \\
7(25 \%) \\
16(57 \%)\end{array}\right\} 18(64 \%)$ & $\left.\begin{array}{l}8 \\
1(13 \%) \\
4(50 \%)\end{array}\right\} 4(50 \%)$ & $\left.\begin{array}{l}20 \\
6(30 \%) \\
12(60 \%)\end{array}\right\} 14(70 \%)$ \\
\hline $\begin{array}{l}\text { Time to relapse (months) } \\
\text { Median } \\
\text { Range }\end{array}$ & $\begin{array}{l}17 \\
(6-24)\end{array}$ & $\begin{array}{l}18 \\
(6-24)\end{array}$ & $\begin{array}{l}17 \\
(7-24)\end{array}$ \\
\hline $\begin{array}{l}\text { After partial response } \\
\text { Primary site } \\
\text { Metastases }\end{array}$ & $\left.\begin{array}{l}17 \\
15(88 \%) \\
15(88 \%)\end{array}\right\} 17(100 \%)$ & $\left.\begin{array}{l}5 \\
5(100 \%) \\
5(100 \%)\end{array}\right\} 5(100 \%)$ & $\left.\begin{array}{l}12 \\
10(83 \%) \\
10(83 \%)\end{array}\right\} 12(100 \%)$ \\
\hline $\begin{array}{l}\text { Time to relapse (months) } \\
\text { Median } \\
\text { Range }\end{array}$ & $\begin{array}{c}6 \\
(3-9)\end{array}$ & $\begin{array}{l}5 \\
(3-6)\end{array}$ & $\begin{array}{c}7 \\
(4-9)\end{array}$ \\
\hline
\end{tabular}


The prognosis for stage III patients was, surprisingly, as poor as for those with stage IV disease with 13 and $15 \%$ respectively, for $2 \frac{1}{2}$-year survival. Two parameters, other than the initial response to chemotherapy, were found to affect the prognosisage at presentation, and gender. Children aged $<1$ year fared significantly better than older children (Fig. 2), in the CV (33\%) and the CVA $(60 \%)$ groups. However, the prognosis for patients aged $>6$ years was no better than for those between 1 and 6 years old, their survival rate being only $9 \%$.

As far as gender was concerned, there was a trend in favour of girls $(27 \%)$ and this was true in the CV- $(40 \%)$ and CVA- $(20 \%)$ treated patients. The difference was not statistically significant $(P>0 \cdot 10)$.

\section{Discussion}

In this series of 69 children with advanced neuroblastoma, $46(69 \%)$ patients treated with pulses of CVA responded to chemotherapy but only 23 $(57 \%)$ treated with pulses of $\mathrm{CV}$ responded. However, this higher incidence of responses attributable to adriamycin was not statistically significant $(P>0.50)$. In addition, the use of adriamycin did not prolong the duration of the remission nor did it increase the number of survivors. These data confirm the results published in 1974 by Gasparini et al. ${ }^{11}$ who, in a small series of 19 patients, found a response rate to CVA of $57 \%$, a median survival time of $17 \cdot 5$ months in patients who responded, and a 2-year survival rate of $17 \%$. More recently, Finklestein et $a l . .^{13}$ showed that the addition of adriamycin to cyclophosphamide, vincristine, and imidazole carboxamide influenced neither the response rate nor the duration of response. In the present series, only patients who responded completely after at least 3 pulses of chemotherapy had a long duration of response which suggests that patients who do not fulfil our criteria for a complete response should be given other treatment. Moreover, criteria for complete response should now include a normal abdominal ultrasound or normal computerised tomography, and even a surgical exploration-since one-quarter of 'complete' responders still relapsed in the primary site when assessed by standard radiological investigations.

It has been suggested that children aged $>6$ years at the time of diagnosis have a better prognosis than younger patients. ${ }^{13}$ This could not be confirmed as only $9 \%$ of our patients were alive and free of disease $2 \frac{1}{2}$ years after diagnosis. However, our data confirm that children aged $<1$ year fared significantly better, with a survival rate of $50 \%$ (Fig. 2). ${ }^{13}{ }^{14}$
The prognosis for survival was worse in boys; this trend has been noted before. ${ }^{15}$

It is concluded that adriamycin did not change the outlook for patients with advanced disease when added to cyclophosphamide and vincristine in this particular 'pulsed' schedule. Before stopping the use of this drug, which is undoubtedly active as a single agent in 30 to $40 \%$ of neuroblastomas, ${ }^{9}$ other schedules should be tried. It has been claimed, for example, that if adriamycin were to be administered on the day after 6 consecutive days of oral cyclophosphamide, the response rate would be higher than if the drugs were given simultaneously. ${ }^{16}$ This clinical effect has been successfully correlated with laboratory studies of the kinetic behaviour of human neuroblastoma ${ }^{17}$ and clearly should be investigated further. Are there other chemotherapeutic agents which show any promise in the treatment of this lethal neoplasm? Response rates of 20 to $66 \%$ have been reported to cis-Platinum ${ }^{18} 19$ and of $23 \%$ to VM-26. ${ }^{20}$ We have investigated the effect of highdose melphalan chemotherapy combined with autologous bone marrow grafting and preliminary results ${ }^{21}$ are encouraging for some patients. We feel that the activity of cis-platinum, VM-26, and melphalan warrants their inclusion in the 'induction' therapy of newly-diagnosed cases of advanced neuroblastoma; analysis of the results of such treatment must examine the contribution of individual agents so that children are not treated unnecessarily with drugs that, while giving respectable response rates as single agents, do not contribute favourably to response, duration, or ultimate survival and which may have significant toxicity. ${ }^{9}$

We thank the paediatricians who referred patients in this study, and Julia Benstead for help with the preparation of the manuscript.

\section{References}

1 Breslow N, McCann B. Statistical estimation of prognosis for children with neuroblastoma. Cancer Res 1971; 31: 2098-103.

2 Leikin S, Evans A, Heyn R, Newton W. The impact of chemotherapy on advanced neuroblastoma. Survival of patients diagnosed in 1956, 1962, and 1962-1968 in Children's Cancer Study Group A. J Pediatr 1974; 84: 131-4.

3 Jaffe N. Neuroblastoma: review of the literature and an examination of factors contributing to its enigmatic character. Cancer Treat Rev 1976; 3: 61-82.

4 Thurman W G, Donaldson M H. Cyclophosphamide (NSC-26271) therapy for children with neuroblastoma. Cancer Chemother Rep 1967; 51 : 399-401.

5 Selawry O S, Holland J F, Wolman I J. Effect of vincristine (NSC-67574) on malignant solid tumors in children. Cancer Chemother Rep 1968; 52: 497-500. 
${ }^{6}$ Evans A E, Heyn R M, Newton W A, Jr, Leikin S L. Vincristine sulfate and cyclophosphamide for children with metastatic neuroblastoma. JAMA 1969; 207: 1325-7.

7 DeVita V T, Jr, Young R C, Canellos G P. Combination versus single agent chemotherapy: a review of the basis for selection of drug treatment of cancer. Cancer 1975; 35: $98-110$.

8 Heyn $R$ M, Holland R, Newton W A, Jr, Tefft $M$, Breslav N, Hartmann J R. The role of combined chemotherapy in the treatment of rhabdomyosarcoma in children. Cancer 1974; 34: 2128-41.

9 Tan C, Etcubanas E, Wollner N, et al. Adriamycin in children with acute leukaemia and other neoplastic diseases. In: Carter S K, DiMarco A, Ghione M, et al., eds. International Symposium on Adriamycin, Milan September 1971. New York: Springer-Verlag, 1972: 204-12.

10 Bonadonna G, Monfardini S, De Lena M, et al. Clinical trials with adriamycin. Results of three years' study. In: Carter S K, Di Marco A, Ghione M, et al., eds. International Symposium on Adriamycin, Milan, September 1971. New York: Springer-Verlag, 1972: 139-52.

11 Gasparini M, Fossati-Bellani F, Musumeli R, Bonadonna G. Response and survival of patients with metastatic neuroblastoma after combination chemotherapy with adriamycin (NSC-123127), cyclophosphamide (NSC26271), and vincristine (NSC-67574). Cancer Chemother Rep 1974 ; 58: 365-70.

12 Evans A E, D'Angio G J, Randolph J. A proposed staging for children with neuroblastoma. Cancer 1971; 27: 374-8.

13 Finklestein J Z, Klemperer M, Evans A, et al. Multiagent chemotherapy for children with metastatic neuroblastoma: a report from Children's Cancer Study Group. Med Pediatr Oncol 1979; 6: 179-88.
14 Etcubanas E, Ertl J. Neuroblastoma in children under 1 year of age. In the proceedings of the Eleventh Meeting of the International Society of Paediatric Oncology, Lisbon, September 1979. Abstract 7,34.

15 Kinnier Wilson L M. Draper G J. Neuroblastoma. Its natural history and prognosis: a study of 487 cases. $B r$ Med J 1974; iii: 301-7.

16 Green A A, Hustu H O, Kumar M. The response of neuroblastoma to sequential low-dose cyclophosphamide (cyclo) and adriamycin (adria) therapy (abstract). Proc Am Assoc Cancer Res 1976; 17: 120.

17 Hayes F A, Green A A, Mauer A M. Correlation of cell kinetic and clinical response to chemotherapy in disseminated neuroblastoma. Cancer Res 1977; 37: 3766-70.

18 Nitschke R, Starling K A, Vats T, Bryan H. Cis-diamminedichloroplatinum (NSC-119875) in childhood malignancies; a Southwest Oncology Group Study. Med Pediatr Oncol 1978; 4: 127-32.

19 Cevik N, Hicsonmez A, Buyukpamukcu $\mathrm{M}$, et al. Treatment of neuroblastoma with cis-platinum. In the proceedings of the Ninth Meeting of the International Society of Pediatric Oncology, Philadelphia, September 1977: 9.

20 Rivera G, Green A A, Hayes F A, Avery T, Pratt C. Epipodophyllotoxin VM-26 in the treatment of childhood neuroblastoma. Cancer Treat Rep 1977; 61 : 1243-8.

21 McElwain T J, Hedley D W, Gordon M Y, Jarman M, Millar J L, Pritchard J. High dose melphalan and noncryopreserved autologous bone marrow treatment of malignant melanoma and neuroblastoma. Exper Hematol 1979; 7: Supplement 5:360-71.

Correspondence to Dr Jon Pritchard, The Hospital for Sick Children, Great Ormond Street, London WC1N 3JH.

Received 15 May 1980 
gluten challenge. The findings suggest that this automated method of tissue analysis is of value in the routine examination of small intestinal biopsies.

We thank Mr E E Wheeler for assistance.

The T M Gregory Memorial Fund and the Hong Kong (Trustees) Limited, Hong Kong and Shanghai Bank, provided generous financial support.

\section{References}

1 Doniach I, Shiner M. Duodenal and jejunal biopsies. II. Histology. Gastroenterology $1957 ; 33: 71-86$.

2 Shiner M, Doniach I. Histopathologic studies in steatorrhea. Gastroenterology 1960; 38: 419-40.

3 Roy-Choudhury D, Cooke W T, Tan D T, Banwell J G, Smits B J. Jejunal biopsy: criteria and significance. Scand J Gastroenterol 1966; 1 : 57-74.

4 Dunnill M S, Whitehead R. A method for the quantitation of small intestinal biopsy specimens. J Clin Pathol 1972; 25: 243-6.

5 Wright S G, Tomkins A M. Quantitative histology in giardiasis. J Clin Pathol 1978; 31 : 712-6.

6 Chapman B L, Henry K, Paice F, Stewart J S, Coghill N F. A new technique for examining intestinal biopsies. Gut 1973; 14: 905-9.

7 Meinhard E A, Wadbrook D G, Risdon R A. Computer card morphometry of jejunal biopsies in childhood coeliac disease. J Clin Pathol 1975; 28 : 85-93.

8 Slavin G, Sowter C, Robertson K, McDermott S, Paton K. Measurement in jejunal biopsies by computer-aided microscopy. J Clin Pathol 1980; 33: 254-61.

Correspondence to Dr D N Challacombe, Somerset Children's Research Unit, Taunton and Somerset Hospital, Musgrove Park, Taunton, Somerset TA1 6DA.

Received 6 November 1980

\section{Erratum}

\section{Chemotherapy of advanced neuro- blastoma: does adriamycin contribute?}

Jacques Ninane, Jon Pritchard, and James S Malpas. We apologise for the fact that Fig. 1 (Arch Dis Child $1981 ; 56: 544-8)$ was incorrect. The correct version is shown below.

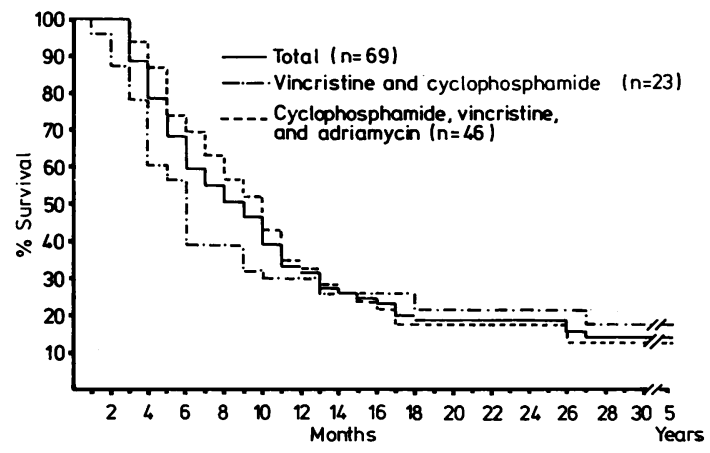

Fig. 1 Survival rate and the effect of adriamycin. 